\title{
Centering in Dynamic Semantics
}

\author{
Daniel Hardt \\ Department of Computing Sciences \\ Villanova University \\ Villanova, PA 19085 \\ hardt@vill.edu
}

\begin{abstract}
Centering theory posits a discourse center, a distinguished discourse entity that is the topic of a discourse. A simplified version of this theory is developed in a Dynamic Semantics framework. In the resulting system, the mechanism of center shift allows a simple, elegant analysis of a variety of phenomena involving sloppy identity in ellipsis and "paycheck pronouns".
\end{abstract}

\section{Introduction}

Centering (Grosz et al., 1995) and Dynamic Semantics ${ }^{1}$ both concern the sequential processing of discourses, with particular emphasis on the resolution of pronouns. In Dynamic Semantics, the semantic structure of a discourse gives rise to constraints on the resolution of anaphoric expressions. Centering theory claims that a discourse always has a single topic, or center. Constraints on the resolution of anaphoric expressions arise, in part, from the ways in which the certer can change in a discourse. There is an important difference in the way discourses are viewed in Centering and in Dynamic Semantics. In Dynamic Semantics, a discourse is viewed as a monotonic increase in information, as discourse referents are constantly added to the domain of discourse. Centering draws attention to a particular role that a discourse entity can hold; from time to time, the current center will be shifted with a new center. In this paper, I will implement a simplified version of the centering theory in a dynamic system, and of phenomena involving sloppy identity in ellipsis and "paycheck pronouns".

Since Montague, a major goal of semantics has been to describe a compositional method for converting a syntactic representation of a sentence into a logical representation of the sentence meaning, and then to evaluate that representation with respect to a given context. A primary insight of dynamic semantics is that sentences have a systematic relation to context in two ways: not only are they evaluated with respect to the current context, but they also systematically change that context. This insight has particular relevance for the apparent puzzle presented by sloppy identity and related phenomena. While anaphoric expressions are normally thought to be identical in meaning to their antecedents, they receive a different interpretation than their antecedents in these cases. Given the dynamic perspective, the puzzle evaporates: the anaphoric expression and its antecedent might represent exactly the same meaning, since meaning is fundamentally a potential to be evaluated with respect to some context. What changes is the context, in the discourse intervening between antecedent and anaphoric expression.

Consider the following example involving sloppy identity in VP ellipsis:

(1) Tom 1 loves his 1 cat. John 1 does too. [loves his 1 cat]

The sloppy reading results from a change in context, in which the value of 1 becomes John rather than Tom. This allows an extremely simple account of the "recovery mechanism" involved in sloppy identity; the elided VP is exactly identical to its antecedent. Several authors (Gardent, 1991; Hardt, 1994) have suggested a dynamic account, along these lines, arguing that sloppy identity and related phenomena reflect the reassignment of an index in the discourse context. ${ }^{2}$

Alternative approaches postulate complex recovery mechanisms for sloppy identity, such as higher-order matching (Dalrymple et al., 1991) or the syntactic matching of parallel dependencies (Fiengo and May, 1994). Below, I will argue that the dynamic account is more general and empirically adequate, as well as being simpler than alternative accounts.

The dynamic account raises the following problem: since the index of the the initial "controller" is reassioned, it becomes inaccessible in subse- 
served for the discourse center, and the discourse center will always occupy another index as well as (). We will use the * to designate references to the discourse center. T'hus the above example will be notatied as follows:

'Iom ${ }_{1 . *}$ loves his $*$ cat. John $2 *$ does too.

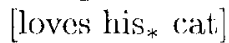

In the first sontence, Tam is the value of index 1, and is also the discourse conter, i.e., the value of index 0 . The pronom his* is equivalent; to his ${ }_{0}$, and thus refers to the discourse center. In the second sentence, John becomes the value of index 2, and also replaces Tom as the discourse center and thus John becomes the value of index 0 . This center shift gives rise to the sloppy reading. However, both Tom and John remain accessible in subsequent discourse.

The paper is organized as follows: In Section 'Two, I present a dynamic framework based on the system described in (Muskens, 1996), with extensions for the discourse center, VP ellipsis, and paycheck pronouns. Section Three concerns an "expanded paradigm" for sloppy identity; it; is shown that the proposed approach unitormly accounts for a broad range of sloppy identity phenomena, including some not previously examined in the literature. Conclusions and plans for future work are given in Section Four.

\section{A Dynamic Framework}

The basic dynamic framework is the dynamic logic system of (Muskens, 1996). This framework has, for the sake of simplicity, restricted the study of anaphora to pronouns that are extensionally identified with their antecedents ${ }^{3}$. I will cxtend Muskens' system to permit anaphora involving VP's as woll as NP's, and to allow antecedents to be dynamic as well as ordinary (extensional) objects.

In Muskens' system, lincarized DRT boxes arc integrated with the type logic (Church, 1940) that underlies Montague Semantics. Linearized DRT boxes are simply a more concise way of writing stiandiard DRT boxes (Kamp, 1980). Muskens shows that DRT boxes can be viewed as abbreviations for expressions in ordinary type logic. Consider the following discourse: the discourse: $A_{1}$ farmer walks. He, laughed.

This is represented by the following linearized DRT box:

$$
\left[\mathrm{u}_{1} \mid \operatorname{farmcr}\left(\mathrm{u}_{1}\right), \operatorname{walk}\left(\mathrm{u}_{1}\right), \operatorname{laugh}\left(\mathrm{u}_{1}\right)\right]
$$

\footnotetext{
${ }^{3}$ There are several researchers who have extended dynamic framoworks to account for ellipsis and related phenomena: (Klein, 1984) is an early examplo. (Asher, 1993) examines a variety of cxtensions to the DRT framework. (van Fijck and Francez, 1993) explore similar issues of indexing and ellipsis in a dynamic setting. (Gardent, 1991) also extends a dynamic semantics system for ellipsis and anaphora.
}

This is an abbreviation for the following type logic formula:

$\lambda i j\left(i\left[u_{1}\right]\right.$ j $\wedge$ farmer $\left(u_{1, j}\right) \wedge$ walks $\left.\left(u_{1, j}\right) \wedge \operatorname{laughs}\left(u_{1} j\right)\right)$

In the above formula, the variables $i$ and $j$ represent input and output states, and the variable $n_{1}$ (akin to a discourse marker) is a function from states to individuals. In what follows, we use the DRT abbreviations without, further comment, The reader is reforred to (Muskens, 1996) for further examples and the details of the system.

We now define a simple fragment of Finglish, based on the one given in (Muskens, 1996).

\begin{tabular}{|c|c|c|}
\hline$a_{n}$ & $\Rightarrow$ & $\lambda \mathrm{P}_{1} P_{2}\left(\left[u_{n} \mid\right] ; \mathrm{P}_{1}\left(u_{n}\right) ; \mathrm{P}_{2}\left(\mathrm{u}_{n}\right)\right)$ \\
\hline $\operatorname{Johm}_{n}$ & $\Rightarrow$ & $\lambda \mathbf{I}\left(\left[u_{n} \mid u_{n}==\right.\right.$ John $\left.] ; \mathbf{P}^{\prime}\left(u_{n}\right)\right)$ \\
\hline $\mathrm{ho}_{n}$ & $\Rightarrow$ & $\lambda \mathrm{I}^{\mathrm{P}} \mathrm{P}(\delta)$ where $\delta=\operatorname{lr}\left(\operatorname{ant}\left(\mathrm{he}_{n}\right)\right)$ \\
\hline if & $\Rightarrow$ & $\lambda \mathrm{pq}[\mid \mathrm{p} \Rightarrow \mathrm{q}]$ \\
\hline $\mathrm{du}$ & $\Rightarrow$ & \\
\hline alk & $\Rightarrow$ & walk $(v)]$ \\
\hline wat & $\Rightarrow$ & $\operatorname{cat}(v)]$ \\
\hline vel & $\Rightarrow$ & $\lambda Q \lambda \mathrm{v}\left(Q\left(\lambda \mathrm{u}^{\prime}\left[\mid \operatorname{loves}\left(\mathrm{v}, \mathrm{u}^{\prime}\right)\right]\right)\right.$ \\
\hline
\end{tabular}

Note that the translation for he ${ }_{n}$ refers to $\operatorname{dr}\left(\right.$ ant $\left.\left(h e_{n}\right)\right)$. This is defined as the discourse rop. resentation of the antecedent, of the $($ see (Muskens, 1996, page 20)). The translation for and is the sequencing operator, ;. As described in (Muskens, 1996), the sequencing of two boxes $K, K^{\prime}$ is an abbreviation for the following type logic expression:

$\left\|K_{1} ; K_{2}\right\| \Rightarrow$

$$
\left.\left\{\langle\mathrm{i}, \mathrm{j}\rangle \mid \exists \mathrm{k}\left(\langle\mathrm{i}, \mathrm{k}\rangle \in \llbracket K_{1} \rrbracket \&<\mathrm{k}, \mathrm{j}\right\rangle \in \llbracket K_{2} \rrbracket\right)\right\}
$$

Typically, two DR'l boxes appearing in sequence can be merged into a single box, consisting of the union of the discourse markers in the two boxes and the union of the conditions. This is clescribed in the Merging Lemma of (Muskens, 1996 page 8). In the representations that follow, wo will often merge boxes without comment to simplify representations. However, the merge of two boxes is not always possible - if there is a reassignment of an index, it will not be possible to perform the morge. This will arise in the casces of sloppy identity examined below.

The above fragment, following the Karnp/Heim accounts, considers only one type of anaphora, involving individuals. We will extend the fragment in the following ways:

- we will add the idca of a discourse center to the system

- we will allow dynamic propertics to be added to contexts, as antecedents for VP ellipsis

- we will allow dynamic individuals to be added to contexts, to account for "paycheck pronouns" 


\subsection{Discourse Center}

We clefine position 0 in the context as the Discourse Center. $\Lambda$ t any given point in the cliscourse, the discourse entity designated as the disconrse center occupies position 0 as woll as its other position. Wo clesignate this with a ${ }^{*}$, as in the following example:

$$
\Lambda_{1}^{*} \text { farmer walks. Hlo* laughed. }
$$

This is represented as follows:

$\left[u_{0}, u_{1} \mid u_{0}=: u_{1}\right.$, farmor $\left(u_{1}\right)$, walk $\left.\left(u_{1}\right), \operatorname{langh}\left(u_{1}\right)\right]$

In this discourse, the entity introduced by $A_{1}$ * farmer is the discourse conter, and thus occupies position 0 as woll as position 1.

We must add additional rules for indefinite expressions and names, when they and an object to context that is the discousse center.

$$
\begin{aligned}
a_{n} * & \Rightarrow \\
\operatorname{Johm}_{n} * & \Rightarrow \mathrm{P}_{1} \mathrm{I}_{2}\left(\left[\mathrm{u}_{0}, \mathrm{u}_{n} \mid \mathrm{u}_{0}:-=\mathrm{u}_{n}\right] ; \mathrm{I}_{1}\left(\mathrm{u}_{n}\right) ; \mathrm{P}_{2}\left(\mathrm{u}_{n}\right)\right) \\
& \lambda \mathrm{P}\left(\left[\mathrm{u}_{0}, \mathrm{u}_{n} \mid \mathrm{u}_{0}=\ldots \mathrm{u}_{n}, \mathrm{u}_{n}=\text { Jolnn }\right] ; \mathrm{P}\left(\mathrm{u}_{n}\right)\right)
\end{aligned}
$$

We will apply a very simplified version of centoring theory, comsisting of the following cont straints:

- Every discourse utteraneo (except tho discourse initial utterance) must have a center.

- If any pronouns occur in an utterance, at least one pronoun must refor to the center.

We define two types of transitions from one utterance to the next:

1. Center Continuation: the centor remains the sarno

2. Center Shift: tho center changes

'I'ho actual centering theory involves an additional data structure, the forward-looking centers, and defines four transition types, with a preference ordering among them. The reater is reforred to (Gros\% ot al., 1995) for a full accomut of this. For our purposes, we will rely on the mechanism of center shift to implenent the reassignment that wo argue is crucial to the dynamic account of slopey identity.

\subsection{VP Ellipsis}

Next, we extend the system for VP' ellipsis: lirst, verbs are separated into a base form and an inflec. tion (INFI). This facilitates the treatment of VP ellipsis; the INIT category adds the now property to the context, just as the determiner "a" adds a now individual to the context. An altormative moaning for the INFL categery is given for VPF occurrences, where a property is aceessed from the input, context.

$\mathrm{INFL}_{u} \Rightarrow \lambda \mathrm{P} \lambda \mathrm{x}\left[\mathrm{P}_{n} \mid \mathrm{P}_{n}=\mathrm{P}^{\mathrm{P}}\right] ; \mathrm{P}(\mathrm{x})$ $\mathrm{INFI}_{s_{n}} \Rightarrow \operatorname{dr}\left(\operatorname{ant}\left(\mathrm{INFI}_{\lrcorner_{n}}\right)\right)$
'The INFT, category ranges over verbal inflex-tions (PAST', PRES, ete.) and anxiliary vertos (do, shouldl, etce. $)^{4}$

Consider the following example of $\mathrm{Vl}^{3}$ ellipsis:

(4) a. 'Tom walks. John does too.

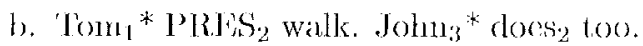

'lhe two sentences receive the following inter protations:

Tom, PRTS walk. $\Rightarrow$

$\left[u_{0}, u_{1}, \mathrm{P}_{2} \mid u_{0}:=: u_{1}, \mathrm{u}_{1}=\right.$ Tom, $P_{2}=\lambda x[\mid$ walk $(\mathrm{x})]$, walk $\left.\left(u_{1}\right)\right]$

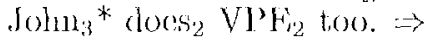

$\left[u_{10}, 1_{3} \mid 1_{0}=11_{3}, 1_{3}=\right.$.Johm $] ; P_{2}\left(1_{3}\right)$

Next, wo join the two sentence interpretations with the sequeneing operator, and we apply the value of $\mathrm{P}_{2}$ to $\mathrm{u}_{3}$ :

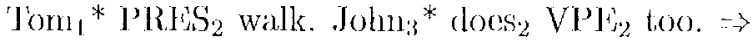
$\left[u_{0}, u_{1}, P_{2} \mid u_{0}=-: u_{1}, u_{1}-\cdots\right.$ Tom, $\left.\Gamma_{2}=\lambda x[\mid \operatorname{walk}(x)], \operatorname{walk}\left(u_{1}\right)\right] ;$

$\left[u_{0}, u_{3} \mid u_{0}=:=1 u_{3}, u_{3}:=\right.$ John, walk $\left.\left(u_{3}\right)\right]$

Next, we will consider an exannple involving sloppy identity. 'To do this, it will be necosisary to add gonitivo NI"'s, such as "his cat" to our system.

lis $\left(\mathrm{he}_{n}{ }^{\prime} \mathrm{s}_{m}\right) \Rightarrow$

$\lambda \mathrm{J}_{1} \mathrm{P}_{2}\left(\left[\mathrm{u}_{m} \mid\right.\right.$ of $\left.\left.\left(\mathrm{u}_{m}, \mathrm{u}_{n}\right)\right] ; \mathrm{P}_{1}\left(\mathrm{u}_{m}\right) ; \mathrm{P}_{2}\left(\mathrm{u}_{m}\right)\right)$

We need two indices: $n$ is the index of he: this is an individual defined in input context. 'T'he index $m$ is the index of the object possessed by he; this object is arlded to the output context. (lor

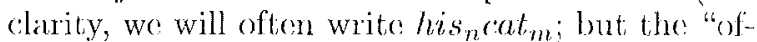
ficial usage" is $h c_{n}$ 's $s_{m}$ cal.)

Now, we examine a simple case of sloppy iclenlity in VP ellipsis:

(5) a. Tom loves his cati. John cloes too.

b. Lom, * PRISS love his* (at, John * doess too.

Tom * P'RI's, love his* (at, $\Rightarrow$

$\left[u_{1}, u_{1}, P_{2}, u_{3} \mid u_{0}=u_{1}, u_{1}:=T^{\prime}\right.$ 'om,

$$
\begin{aligned}
& l_{2}=\lambda x\left(\left[u_{3} \mid\right.\right. \text { of }\left(u_{3}, u_{0}\right), \\
&\left.\left.\operatorname{cat}\left(u_{3}\right), \operatorname{love}\left(x, u_{3}\right)\right]\right),
\end{aligned}
$$

. $\operatorname{Iohm}_{4} *$ doesis $_{2}(100) \rightarrow$ of $\left(u_{3}, u_{0}\right)$, caul, $\left(u_{3}\right)$, love $\left.\left(u_{1}, u_{3}\right)\right]$

$\left[u_{0}, u_{4} \mid u_{4}==u_{0}, u_{4}=J o h n\right] ; \mathbb{P}_{2}\left(u_{4}\right)$

Next, we join the two sentences together and apply the value of $\mathrm{P}_{2}$ to $\mathrm{ul}_{4}$ :

\footnotetext{
"We ignore the somantic conbribution of INFl, apart from the above-described interaction with the discourse context.
} 
Tom $_{1} * \mathrm{PRES}_{2}$ love his* cat $_{3}$ (and)

$\operatorname{John}_{4} * \operatorname{does}_{2}$ (too) $\Rightarrow$

$\left[\mathrm{u}_{0}, \mathrm{u}_{1}, \mathrm{P}_{2}, \mathrm{u}_{3} \mid \mathrm{u}_{0}=\mathrm{u}_{1}, \mathrm{u}_{1}=\right.$ Tom,

$\mathrm{P}_{2}=\lambda \mathrm{x}\left[\mathrm{u}_{3} \mid\right.$ of $\left(\mathrm{u}_{3}, \mathrm{u}_{0}\right)$, $\operatorname{cat}\left(u_{3}\right)$, love $\left.\left(x, u_{3}\right)\right]$, of $\left(u_{3}, u_{0}\right), \operatorname{cat}\left(u_{3}\right)$, love $\left.\left(u_{1}, u_{3}\right)\right]$;

$\left[\mathrm{u}_{0}, \mathrm{u}_{4} \mid \mathrm{u}_{4}=\mathrm{u}_{0}, \mathrm{u}_{4}=\right.$ John $]$;

$\left[\mathrm{u}_{3} \mid\right.$ of $\left(\mathrm{u}_{3}, \mathrm{u}_{0}\right), \operatorname{cat}\left(\mathrm{u}_{3}\right)$, love $\left.\left(\mathrm{u}_{4}, \mathrm{u}_{3}\right)\right]$

The antecedent for the VPE is "love his cat". This object $\left(\mathrm{P}_{2}\right)$ is introduced into the context by PRES $_{2} . \mathrm{P}_{2}$ represents the property of "loving $\mathrm{u}_{0}$ 's cat", where $u_{0}$ is the discourse center defined in the input context. In the first sentence, the center is TOM. The second sentence shifts the center to JOHN. It is this change in context that gives rise to the sloppy reading. Thus a sloppy reading is made possible when there is a center shift.

Finally, we allow the possibility that a property might be the discourse center. This means wo must add an alternative rule for INFL, so that it adds a property that is the discourse center:

$\mathrm{INFL}_{n}{ }^{*} \Rightarrow$

$$
\lambda \mathrm{P} \lambda \mathrm{x}\left[\mathrm{P}_{n} \mid \mathrm{P}_{0}=\mathrm{P}_{n}, \mathrm{P}_{n}=\mathrm{P}\right] ; \mathrm{P}(\mathrm{x})
$$

\subsection{Paycheck Pronouns}

The phenomenon of "paycheck pronouns", 5 is illustrated by the following example

Smith spent his paycheck. Jones saved it.

The reading of interest is where the pronoun "it" refers to Jones' paycheck, although its antecedent ("his paycheck") refers to Smith's paycheck. Our account, for this parallels the account of sloppy identity in VP cllipsis. The antecedent

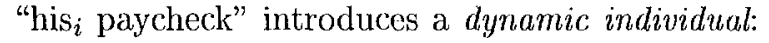
a relation between contexts that introduces i's paycheck to the output context, where the value of $i$ is determined by the input context. The following rule makes it possible for NP's like "his paycheck" to add dynamic individuals to the context.

$$
\begin{aligned}
& \underset{\operatorname{his}\left(\text { he }_{n}{ }^{\prime} \mathrm{s}_{m}\right) \Rightarrow}{\Rightarrow} \\
& \qquad \mathrm{P}_{1} \mathrm{P}_{2}\left[\mathrm{x}_{m} \mid \mathrm{x}_{m}=\lambda \mathrm{P} \underset{\mathrm{x}_{m}\left(\mathrm{P}_{2}\right)}{\stackrel{\left(\left[\mathrm{u}_{m} \mid \text { of }\left(\mathrm{u}_{m}, \mathrm{u}_{n}\right)\right]\right.}{\left.\mathrm{P}_{1}\left(\mathrm{u}_{m}\right) ; \mathrm{P}\left(\mathrm{u}_{m}\right)\right) ;}}\right.
\end{aligned}
$$

${ }^{5}$ This term comes from Kartunnen's example: The man who gave his paycheck to his wife was wiser than the one who gave it to his mistress. Various accounts of this phenomenon have been proposed, such as (Cooper, 1979; Engdahl, 1986; Jacobson, 1992; Gardent, 1991). (Heim, 1990) proposed extending the Sag/Williams account of VPE to the case of paycheck pronouns. Gardent makes a proposal similar to the current account: a dynamic approach in which paycheck pronouns and VPE are treated uniformly.
We use variables of the form $u_{i}$ to denote ordinary extensional individuals; we use variables of the form $x_{i}$ to denote dynamic individuals. There are two distinct effects on the output context. First, the dynamic individual $\mathrm{x}_{m}$ is added to context: this object adds an individual $u_{m}$ to a given context, such that $\mathrm{u}_{m}$ is of $\mathrm{u}_{n}$ in that context. Second, $\mathrm{x}_{m}$ is applied to the property $\mathrm{P}_{2}$. This actually adds $u_{m}$ to the current context.

Finally, we need an alternative form for pronouns that refer to dynamic individuals:

he $\boldsymbol{e}_{n} \quad \Rightarrow \quad \delta$ where $\delta=\operatorname{dr}\left(\operatorname{ant}\left(\right.\right.$ he $\left.\left._{n}\right)\right)$

The pronoun he recovers $_{n}$ from the current, context. The desired reading can now be dorived as follows:

(7) a. Smith spent, his paycheck. Jones saved it.

b. Smith $_{1} *$ PAST $_{2}$ spend his* paycheck $_{3}$. Jones $_{4} * \mathrm{PAST}_{5}$ save it .

We take the two sentences individually. The first sentence introduces the dynamic individual $\mathrm{x}_{3}$, as follows ${ }^{6}$ :

his* $^{*}$ paycheck $_{3} . \Rightarrow$

$\lambda \mathrm{P}_{2}\left[\mathrm{x}_{3} \mid \mathrm{x}_{3}=\lambda \mathrm{P}\left(\left[\mathrm{u}_{3} \mid\right.\right.\right.$ of $\left(\mathrm{u}_{3}, \mathrm{u}_{0}\right)$, paycheck $\left.\left(\mathrm{u}_{3}\right)\right]$; $\mathrm{x}_{3}\left(\mathrm{P}_{2}\right)$ $\left.\left.\mathrm{P}\left(\mathrm{u}_{3}\right)\right)\right]$;

spend his* paycheck ${ }_{3} . \Rightarrow$

$\lambda \mathrm{v}\left[\mathrm{x}_{3} \mid \mathrm{x}_{3}=\lambda \mathrm{P}\left(\left[\mathrm{u}_{3} \mid\right.\right.\right.$ of $\left(\mathrm{u}_{3}, \mathrm{u}_{0}\right)$, paycheck $\left.\left(\mathrm{u}_{3}\right)\right]$; $\left.\left.\mathrm{P}\left(\mathrm{u}_{3}\right)\right)\right]$; $\mathrm{x}_{3}\left(\lambda \mathrm{u}^{\prime}\left[\mid \operatorname{spend}\left(\mathrm{v}, \mathrm{u}^{\prime}\right)\right]\right)$

spend his* paycheck ${ }_{3} . \Rightarrow$

$\lambda \mathrm{v}\left[\mathrm{x}_{3} \mid \mathrm{x}_{3}=\lambda \mathrm{P}\left(\left[\mathrm{u}_{3} \mid\right.\right.\right.$ of $\left(\mathrm{u}_{3}, \mathrm{u}_{0}\right)$, paycheck $\left.\left(\mathrm{u}_{3}\right)\right]$; $\left.\left.\mathrm{P}\left(\mathrm{u}_{3}\right)\right)\right]$

$\left[u_{3} \mid\right.$ of $\left(u_{3}, u_{0}\right)$, paycheck $\left.\left(u_{3}\right)\right] ;\left[\mid \operatorname{spend}\left(v, u_{3}\right)\right]$

Smith ${ }_{1} * \mathrm{PAST}_{2}$ spend his* paycheck $_{3} . \Rightarrow$

$\left[\mathrm{u}_{0}, \mathrm{u}_{1}, \mathrm{P}_{2}, \mathrm{x}_{3} \mid \mathrm{u}_{0}=\mathrm{u}_{1}, \mathrm{u}_{1}=\right.$ Smith, $\mathrm{x}_{3}=\lambda \mathbf{P}\left(\left[\mathrm{u}_{3} \mid\right.\right.$ of $\left.\left(\mathrm{u}_{3}, \mathrm{u}_{0}\right), \operatorname{paychcck}\left(\mathrm{u}_{3}\right)\right]$ $\left.\left.\mathrm{P}\left(\mathrm{u}_{3}\right)\right)\right]$;

$\left[\mathbf{u}_{3} \mid\right.$ of $\left.\left(\mathrm{u}_{3}, \mathrm{u}_{0}\right), \operatorname{paycheck}\left(\mathrm{u}_{3}\right), \operatorname{spend}\left(\mathbf{u}_{1}, \mathbf{u}_{3}\right)\right]$

We continue with the second sentence.

save $\mathrm{it}_{3} \Rightarrow$

$$
\lambda \mathrm{Q} \lambda \mathrm{v}\left(\mathrm{Q}\left(\lambda \mathrm{u}^{\prime}\left[\mid \operatorname{save}\left(\mathrm{v}, \mathrm{u}^{\prime}\right)\right]\right)\right) \operatorname{dr}\left(\operatorname{ant}\left(\mathrm{it}_{3}\right)\right)
$$

We substitute the value of $\mathrm{x}_{3}$ for $d r\left(\operatorname{ant}\left(i t_{3}\right)\right)$ :

save $\mathrm{it}_{3} \Rightarrow$

$\lambda \mathrm{Q} \lambda \mathrm{v}\left(\mathrm{Q}\left(\lambda \mathrm{u}^{\prime}\left[\mid \operatorname{save}\left(\mathrm{v}, \mathrm{u}^{\prime}\right)\right]\right)\right)$

$\lambda \mathrm{P}\left(\left[\mathbf{u}_{3} \mid\right.\right.$ of $\left.\left.\left.\left(\mathbf{u}_{3}, \mathbf{u}_{0}\right), \operatorname{paycheck}\left(\mathrm{u}_{3}\right)\right] ; \mathrm{P}\left(\mathbf{u}_{3}\right)\right)\right]$

We perform $\lambda$ reductions, resulting in:

\footnotetext{
${ }^{6}$ To simplify the representation, we omit the values for $V P$ variables $P_{2}$ and $P_{5}$, since they arc not relevant
} to the current example. 


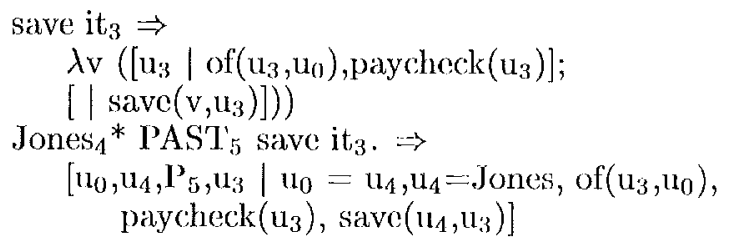
lows:

The complete discourse is represented as fol-

Smith ${ }_{1}^{*}$ PAST $_{2}$ spend his* paycheck

Jones, $_{4} * \mathrm{PAST}_{5}$ save $\mathrm{it}_{3}$. $\Rightarrow$

$\left[\mathrm{u}_{0}, \mathrm{u}_{1}, \mathrm{P}_{2}, \mathrm{x}_{3} \mid \mathrm{u}_{0}=\mathrm{u}_{1}, \mathrm{u}_{\mathrm{J}}=\right.$ Sinith,

$\mathrm{x}_{3}=$

$\lambda \mathrm{P}^{\mathrm{P}}\left(\left[\mathrm{u}_{3} \mid\right.\right.$ of $\left(\mathrm{u}_{3}, \mathrm{u}_{0}\right)$, paycheck $\left.\left.\left(\mathrm{u}_{3}\right)\right] ; \mathrm{I}^{\prime}\left(\mathrm{u}_{3}\right)\right)$

$\left[u_{3} \mid\right.$ of $\left(u_{3}, u_{0}\right)$, paycheck $\left(u_{3}\right)$, spend $\left.\left(u_{1}, u_{3}\right)\right]$;

$\left[\mathrm{u}_{0}, \mathrm{u}_{4}, \mathrm{P}_{5}, \mathrm{u}_{3} \mid \mathrm{u}_{0}=\mathrm{u}_{4}, \mathrm{u}_{4}=\right.$ Jones, of $\left(u_{3}, u_{0}\right)$, paycheck $\left(u_{3}\right)$, save $\left.\left(u_{4}, u_{3}\right)\right]$

The dynamic individual $\mathrm{x}_{3}$ adds the paycheck of $u_{0}$ (the discourse center) to the context. In the second sentence, the discourse conter is Jones. Thus we get the reading in which "Jones saved Jones' paychock", as desired.

\section{An Expanded Paradigm for Sloppy Identity}

The proposed theory permits a simple, uniform treatment of sloppy identity in VPE and paycheck pronouns. 'This uniformity extends further. We simply permit sloppy identity for any proform, whenever the antecedent contains a proform within it. This is schematically represented as follows:

\section{C $1 \ldots[X I, \ldots[Y P] \ldots] \ldots \mathrm{C} 2 \ldots\left[X l^{\prime \prime}\right]$}

(C1, C2: "controllors" of sloppy variable YP)

Here, $X Y$ is the antecedent for some proform $X P^{\prime}$, and $Y P^{\prime}$ is the sloppy variable, i.c., a proform embedded within $X P$. $\Lambda$ sloppy reading results whenever there is a center shift involving $\mathrm{C} 1$ and $\mathrm{C} 2$. That is, the interpretation of $Y P$ switches from controller $C 1$ to $C 2$.

Since the dynamic theory treats VP' cllipsis uniformly with NP proforms, $X P$ and $Y I$ ' both range over $N P$ and $V P$. This predicts four possibilities. All four possibilities in fact occur, as shown by the following examples:

Tom $[V I$ loves $[N I$, his $]$ cat $]$. John does too.

Smith spent [NI, [NP, his] paycheck]. Jones saved it.

I'll help you if you lVI, want me to $[v P]]$. I'll kiss you even if you don't. ${ }^{7}$

\footnotetext{
${ }^{7}$ This example was provided by Marc Gawron (p.c.), who attributed it to Carl Pollard.
}

When Harry drinks, I always conceal $[N P$ my belief that he shouldn't $[V P]]$. Whon he gambles, 1 can't conceal it.

Fixamples (8) and (9) have already been discussed. (8) is the familiar case in which the VP antecedent $(X P)$ contains a sloppy pronoun $(Y P)$. $Y P^{\prime}$ switches from $C 1$, Tom, to $C 2$, John. In example (9), we have an NP antecedent $(X P)$ containing a sloppy pronoun $(Y P)$, and the two controllers for $Y P$ are Smith and Jones. Example (10) involves a VP antecedent containing a sloppy VP ellipsis; the VP ellipsis switches from help you to kiss you. Finally, example (11) involvos an NP antecedent containing a sloppy VP ellipsis, switching from drinks to gambles.

We have alroady seen how the sloppy reading is derived for (8) and for (9). We now show the derivation for (10) (example (11) can be derived in a similar fashion. $)^{8}$ :

$\mathrm{I}_{1}$ WII $_{2} *$ help you $_{3}$ [if] you PRES $_{4}$ want me $\mathrm{to}_{2}$.

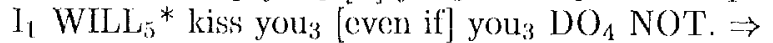

$\left[u_{1}, P_{0}, P_{2}, u_{3}, P_{4} \mid u_{1}=1, P_{0}=P_{2}, u_{3}=\right.$ You,

$$
\begin{aligned}
& \mathrm{P}_{2}=\lambda \mathrm{v}\left(\left[\mid \operatorname{hel} \mathrm{p}\left(\mathrm{v}, \mathrm{u}_{3}\right)\right]\right), \\
& \mathrm{P}_{1}=\lambda \mathrm{v}\left(\left[\mid \operatorname{want}\left(\mathrm{v}, \mathrm{P}_{0}\left(\mathrm{u}_{1}\right)\right)\right]\right),
\end{aligned}
$$

help $\left(\mathrm{u}_{1}, \mathrm{u}_{3}\right)$, want $\left.\left(\mathbf{u}_{1}, \operatorname{hel} p\left(\mathrm{u}_{1}, \mathbf{u}_{3}\right)\right)\right]$;

$\left[\mathbf{P}_{0}, \mathbf{P}_{5} \mid P_{0}=\mathbf{P}_{5}\right.$

$$
\left.\mathbf{P}_{5}=\lambda v\left(\left[\mid \operatorname{kiss}\left(\mathrm{v}, \mathrm{u}_{3}\right)\right]\right), \mathrm{NO}^{\prime} \mathrm{T}\left(\mathrm{P}_{4}\left(\mathrm{u}_{3}\right)\right)\right]
$$

The variable $P_{4}$ represents the property of "wanting $\mathrm{u}_{1}$ to $\mathbf{P}_{0}$ ". Below, we substitute the value $\lambda v\left(\left[\mid\right.\right.$ want $\left.\left.\left(v, P_{0}\left(u_{1}\right)\right)\right]\right)$ for $P_{A}$, ancl then substitute the value $\lambda v\left(\left[\mid\right.\right.$ help $\left.\left.\left(v, 1_{3}\right)\right]\right)$ for $\mathrm{P}_{0}$, and apply it to $1_{3}$, giving the following result:

$I_{1}$ WILI $_{2} *$ help you 3 [if] your PRES $_{4}$ want me to to $_{2}$ $\mathrm{I}_{1}$ WIJ $_{5} *$ kiss you 3 [even if] $\mathrm{you}_{3} \mathrm{I}_{4} \mathrm{O}_{4} \mathrm{NO}^{\prime} \mathrm{T} . \Rightarrow$ $\left[\mathrm{u}_{1}, \mathrm{P}_{0}, \mathrm{P}_{2}, \mathrm{u}_{3}, \mathrm{P}_{4} \mid \mathrm{u}_{1}=\mathrm{I}, \mathrm{P}_{0}=\mathrm{P}_{2}, \mathrm{u}_{3}=\mathrm{You}\right.$, $P_{2}=\lambda v\left(\left[\mid \operatorname{hol} \mathrm{p}\left(\mathrm{v}, \mathrm{u}_{3}\right)\right]\right)$ $\mathrm{P}_{4}=\lambda \mathrm{v}\left(\left[\mid \operatorname{want}\left(\mathrm{v}, \mathrm{P}_{0}\left(\mathrm{u}_{1}\right)\right)\right]\right)$, $\operatorname{holp}\left(u_{1}, u_{3}\right)$, want $\left.\left(u_{1}, \operatorname{help}\left(u_{1}, u_{3}\right)\right)\right]$;

$\left[P_{0}, P_{5} \mid P_{0}=P_{5}, P_{5}=\lambda v\left(\left[\mid \operatorname{kiss}\left(v, u_{3}\right)\right]\right)\right.$, $\operatorname{NOT}\left(\left[\mid\right.\right.$ want $\left.\left.\left(u_{3}, \operatorname{kiss}\left(u_{1}, u_{3}\right)\right)\right]\right)$,

It is the "center shift" involving $P_{2}$ ("help you") and $P_{5}$ ("kiss you") that makes the desired reading possible. That is, "what, $u_{3}$ doesn't want is for $\mathrm{u}_{1}$ to kiss $\mathrm{u}_{3}$ ".

The dynamic theory explains all four of these cases in the same way; the embedded proform in the antecedent, can be sloppy, because the controller for the embedded proform can undergo a center shift. The cases illustrated by (10) and (11)

\footnotetext{
${ }^{8}$ We construct a representation as if the connectives if and even if were simple conjunctions. This allows us to avoid the complex issues involved in representing such "backwards conditionals" in a dynamic system.
} 
have not, to my knowledge, been discussed previously in the literature. It is not clear how such $\mathrm{ex}$ amples could be handled by alternative theories, such as (Fiengo and May, 1994) or (Dalrymple ot al., 1991), since these theories do not treat $\mathrm{NP}$ and VP anaphora in a uniform fashion.

\section{Conclusions and Future Work}

The dynamic perspective provides a framework for a simple, intuitive account of sloppy identity and related phenomena, by explaining the interpretive facts in terms of changes in context. This requires contexts to change in a way that is somewhat foreign to the dynamic perspective; a given position in the context must be reassigned, or shift its value. To implement, this, I have incorporated the notion of discourse center, together with the mechanism of center shift, into a dynamic system. 'This makes it possible to give a novel, dynamic account of sloppy identity phenomena. I have shown that this approach accounts for an expanded paradigm of sloppy identity, going beyond the data addressed in alternative accounts. In future work, we will investigate incorporating additional aspects of centering theory, including the forward-looking conters list, and the pueference orderings on transitions.

\section{Acknowledgments}

Thanks to Claire Gardent, Aravind Joshi, Shalom Lappin, Mats Rooth, Stuart Shieber, Mark Stecdman, and Bonnie Webber for holp in developing the basic approach described in this paper. Thanks to Reinhard Muskens for helpful comments on an earlier version of this work. This work was partially supported by a Villanova University Summer Research Grant (1995), and an NSF Carcer Grant, no. IRI-9502257.

\section{References}

Nicolas Asher. 1993. Reference to Abstract Objects in English. Dordrecht.

Gennaro Chicrchia. 1992. Anaphora and dynamic interpretation. Linguistics and Philosophy, 18.

Alonzo Church. 1940. A formulation of the simple theory of typos. The Journal of Symbolic Logic, $5: 5668$

Robin Cooper. 1979. The interpretation of pronouns. In F. Heny and H. Schnelle, editors, Syntax and Semantics 10. Acadomic Press.

Mary Dalrymple, Stuart Shieber, and Fernando Pereira. 1991. Ellipsis and higher-order unification. Linguistics and Philosophy, 14(4), August.

Elisabeth Engdahl. 1986. Constituent Questions. D. Riedel, Dordrecht, Netherlands.
Robert Fiengo and Robert May. 1994. Indices and Identity. MI' Press, Cambridge, MA.

Claire Gardent. 1991. Dynamic: semantics and vp-ellipsis. In J. van Fijck, editor, Logies in AI, Lecture notes in Artificial Intelligence 478 . Springer, Borlin.

Jeroen Groenendijk and Martin Stokhof. 1992. Dynamic predicato logic. Linguistics and Plitlosophy.

Barbara Grosz, Aravind Joshi, and Scott Weinstein. 1995. Centering: A framework for modang the local coherence of a discourse. Computational Linguistics, 21(2).

Daniel Hardt. 1994. Sense and reference in dynamic semantics. In Proceedings of the Ninth Amsterdam Colloquium.

Irene Heim. 1982. The Semantics of Definite and Indefinite Noun Phrases. Ph.J). thesis, University of Massachusetts-Amhorst.

Irene Heim. 1990. E-type pronouns and donkey anaphora. Linguistics and Philosophy, 13(2).

Pauline Jacobson. 1992. Antecedent contained deletion in a variable-free semantics. In Proceedings of the Second Conference on Semantics and Linguistic Theory, Columbus, Ohio.

Hans Kamp. 1980. A theory of truth and semantic representation. In J. Groenendijk, T.M.V. Janssen, and M. Stokhof, editors, Formal Methods in the: Study of Language, pages 277322. Dordrecht. Volume 136.

Chris Konnedy. 1993. Argument-contained allipsis.

Ewan Klein. 1984. Vp cllipsis in de theory.

Reinhard Muskens. 1996. Combining montaguo semantics and discourse representation. Iin guistics and Philosophy.

Jan van Fijck and Nissim France. 1993. Procedural dynamic somantics, verb-phrase ellipsis, and presupposition. In CWI, Report CSR.9311. 